\title{
Numerical Simulation of Coal Spontaneous Combustion around a Borehole Induced by Negative Pressure Gas Drainage
}

\author{
Youxin Zhao $\mathbb{D}^{1,2}$ Qingjie Qi, ${ }^{1,2}$ Xinlei Jia $\mathbb{D}^{3,4}$ Yingjie Liu $\mathbb{D}^{1,2}$ and Jingwen Zhang ${ }^{1,2}$ \\ ${ }^{1}$ Emergency Science Research Academy, China Coal Research Institute, China Coal Technology \& Engineering Group Co., Ltd., \\ Beijing 100070, China \\ ${ }^{2}$ State Key Laboratory of Efficient Mining and Clean Utilization of Coal Resources, Beijing 100013, China \\ ${ }^{3}$ School of Safety Science and Engineering, Liaoning Technical University, Fuxin Liaoning 123000, China \\ ${ }^{4}$ Key Laboratory of Mine Thermodynamic Disasters and Control of Ministry of Education, Fuxin Liaoning 123000, China \\ Correspondence should be addressed to Xinlei Jia; ybyyfz@163.com
}

Received 22 April 2021; Revised 18 June 2021; Accepted 27 July 2021; Published 9 August 2021

Academic Editor: Bo Tan

Copyright (C) 2021 Youxin Zhao et al. This is an open access article distributed under the Creative Commons Attribution License, which permits unrestricted use, distribution, and reproduction in any medium, provided the original work is properly cited.

\begin{abstract}
The suction negative pressure is an important factor affecting the spontaneous combustion of coal around a borehole. Because the mechanism of suction negative pressure in the gas extraction process remains unclear, a constant suction negative pressure is often used in coal mines, leading to a low efficiency of gas extraction in deep coal seams. Moreover, the coal body easily undergoes spontaneous combustion during the extraction process, which is not conducive to safe mining. To study the effect of the suction negative pressure near the end sealing section, a numerical model of the combustion process around a borehole under the influence of suction negative pressure was established using COMSOL. The variation laws of the gas seepage velocity, oxygen concentration, and coal temperature in the borehole cycle were analyzed, and the gas suction negative pressure under different sealing parameters was optimized to ensure efficient gas extraction and prevent the spontaneous combustion of coal. The results showed that the negative pressure of extraction provides the power required for gas seepage into the borehole, and the gas flow rate increases with increasing negative pressure of extraction, exhibiting a linear growth trend. The range of the coal suffocation zone around the sealing section decreases with the increase in the negative pressure. With the extension of the gas extraction time, the oxygen concentration decreases rapidly, and the inflection point advances with the increase in the negative pressure. When the negative pressure of gas extraction is $<40 \mathrm{kPa}$, the range of the high-temperature area around the block increases with the negative pressure of gas extraction. Based on the present situation of the spontaneous combustion induced by gas drainage in the Pingdingshan No. 10 Coal Mine, different sealing parameters should be set with different negative pressures of extraction, and the negative pressure of extraction should not exceed $-18 \mathrm{kPa}$ when the sealing depth is $20 \mathrm{~m}$ and the sealing length is $8 \mathrm{~m}$ in the 24130 working face. These parameter settings can help effectively prevent spontaneous combustion during the extraction process.
\end{abstract}

\section{Introduction}

The negative pressure of gas extraction is one of the main indices affecting the progress of gas extraction in coal mines [1-5]. In the process of gas drainage along the bed, the negative pressure provides the power for gas extraction, and the gas and surrounding gas continuously flow into the extraction pipe through the fissured coal around the plugging sec- tion, thus realizing gas extraction. An excessive negative pressure not only reduces the gas concentration in the borehole but also increases the oxygen content around the fissured coal, leading to a spontaneous combustion of the coal around the borehole. A low negative pressure increases the extraction time, and performing the extraction for a long duration can also easily lead to a spontaneous combustion. Therefore, setting a reasonable negative pressure for gas 
extraction has important guiding significance for improving the gas extraction efficiency, shortening the construction period, and ensuring the safety of gas extraction [6].

Several theoretical and experimental studies have been conducted on the negative pressure and gas extraction efficiency. Liu et al. [7] proposed a mechanism-based model to theoretically describe the gas desorption, diffusion, and flow through coal around a drainage borehole. The proposed model was numerically solved and verified with borehole drainage data obtained from a mine site. Zhang et al. [8] designed a simulation test platform and performed a numerical simulation on the gas seepage characteristics. The optimal negative pressure of extraction was between $30 \mathrm{kPa}$ and $40 \mathrm{kPa}$, and the extraction concentration was the highest at $35 \mathrm{kPa}$. Qi et al. determined the spontaneous combustion area of coal around a gas drainage borehole and optimized the gas drainage negative pressure using numerical simulation software, with the air flow velocity as the criterion [911]. The effects of gas concentration and coal spontaneous combustion characteristics on gas seepage and coal spontaneous combustion have been analyzed on the basis of the gas seepage theory, control equation, and combustion calculation model [12-17].

Despite the numerous studies on negative pressure drainage $[18,19]$, currently, the mechanism of spontaneous combustion induced by the negative pressure remains unclear, and a constant negative pressure is generally used in the gas drainage of coal mines. Some research results have shown that with the change in the sealing parameters, coal seam depth, and geological conditions, the gas leakage channel around the borehole changes significantly [20-22]. Moreover, with the increase in the gas extraction time, the surrounding oxygen concentration, seepage distribution, and coal temperature vary. The use of the constant negative pressure cannot solve the problem of gas extraction and coal spontaneous combustion. Based on the actual conditions in a mine, selecting reasonable drainage parameters is beneficial to improving the efficiency of coal seam gas drainage [23]. However, increasing the negative pressure of extraction aggravates the spontaneous combustion of the coal around the borehole [24-27]. Because of the particularity and complexity of the coal body environment around the gas extraction borehole, it is difficult to directly observe the surrounding gas concentration, seepage velocity distribution, and coal body temperature during the gas extraction process. Moreover, the laws of temporal and spatial evolutions cannot be directly reflected. A reasonable negative pressure for extraction is the key to solving the problems related to the gas extraction and coal spontaneous combustion zone around the borehole $[28,29]$.

Although considerable research has been conducted on negative pressure drainage, there are few studies on the mechanism of coal spontaneous combustion induced by the negative pressure. Based on the actual sealing situation of the 24130 working face of Pingdingshan No. 10 Mine and considering gas diffusion, permeability variation, coal oxidation reaction, and porous media heat transfer, this study established a gas drainage coupling model under different drainage negative pressure conditions. The simulation results reveal the variations in the gas concentration, seepage distribution, and coal temperature around the borehole; help analyze the negative pressure of drainage under different sealing parameters; and lay a theoretical foundation for ensuring safe and efficient gas drainage.

\section{Mathematical Modeling of Spontaneous Combustion of Coal around Boreholes Induced by Gas Drainage}

2.1. Darcy's Law. The fractured coal body around a borehole is considered a porous medium space with nonuniform porosity and permeability. The permeability is a continuous function [30-32]. The gas seepage velocity in the porous medium can be expressed as in

$$
\begin{aligned}
\frac{\partial}{\partial t}\left(\varepsilon_{p} \rho\right)+\nabla \cdot(\rho \mu) & =Q_{m}, \\
v & =-\frac{k}{2 \mu p_{1}} \frac{d P}{d l} .
\end{aligned}
$$

In Equations (1) and (2), $\varepsilon_{p}$ is the porosity, and the unit is $1 ; \nabla$ is the flow gradient; $\rho$ is the mixed gas density, $\mathrm{kg} / \mathrm{m}^{3} ; p_{1}$ is the negative pressure, $\mathrm{Pa} ; v$ is the vector velocity of the airflow, $\mathrm{m} / \mathrm{s} ; \mu$ is the dynamic viscosity of the mixed gas; $k$ is the permeability, $\mathrm{m}^{2}$.

2.2. Mass Transfer in Porous Media. The combustion of air in the fractured coal body around a borehole is a complicated process, and the volume fraction of the gas in the porous medium is affected by multiphysical parameters.

\subsubsection{Governing Equation for the Gas around the Borehole.}

$$
\begin{array}{r}
p_{2, j} \frac{\partial c_{i}}{\partial t}+p_{1, \mathrm{i}}+\nabla \cdot \Gamma_{i}+u \cdot \nabla c_{i}=R_{i}+S \\
p_{3, j}=\triangle_{p} .
\end{array}
$$

In Equations (3) and (4) [29], $p_{2}$ is the original rock stress, $\mathrm{MPa} ; R_{i}$ is the reaction rate, $\mathrm{mol} /\left(\mathrm{m}^{3} \cdot \mathrm{s}\right), p_{3}$ is the roadway pressure, $\mathrm{MPa} ; \triangle_{p}$ is the pressure of the coal body around the borehole, MPa.

The equations governing the gas diffusion process are as follows:

$$
\begin{aligned}
p_{1, i} & =c_{i} \frac{\partial \triangle_{p}}{\partial t}, \\
N_{i} & =\Gamma_{i}+u c_{i}=-D_{e, j} \nabla c_{i}+u c_{i}, \\
D_{e, j} & =\frac{\triangle_{p}}{\tau_{F, j}} D_{F, j},
\end{aligned}
$$

where $D_{e, j}$ is the diffusion coefficient of different gases, $\mathrm{m}^{2} / \mathrm{s}$.

2.2.2. Coal Oxidation Reaction Equation. The air around the borehole reacts chemically with the coal, and the governing equation for the oxygen consumption reaction is as follows: 


$$
\frac{\partial c_{i}}{\partial t}+\nabla \cdot\left(-D_{i} \nabla c_{i}\right)+u \nabla c_{i}=R_{i}
$$

The oxygen consumption rate in Equation (6) is related to factors such as the coal spontaneous combustion characteristics, oxygen concentration, and temperature. The temperature and oxygen volume fraction have a greater impact on the oxygen consumption rate of the fractured coal body around the borehole. According to literature [33], the following is the general expression for the oxygen consumption rate:

$$
R_{\mathrm{c}}=-\frac{c\left(\mathrm{O}_{2}\right)}{c^{0}\left(\mathrm{O}_{2}\right)} \gamma_{0} e^{\alpha\left(T-T_{\Gamma}\right)} .
$$

In Equation (7), $R_{\mathrm{c}}$ is the oxygen consumption coefficient, $\mathrm{mol} /\left(\mathrm{m}^{3} \cdot \mathrm{s}\right) ; c^{0}\left(\mathrm{O}_{2}\right)$ is the initial oxygen concentration, $1 ; c\left(\mathrm{O}_{2}\right)$ is the actual oxygen concentration, $1 ; T$ is the absolute temperature of the coal body, ${ }^{\circ} \mathrm{C} ; T_{\Gamma}$ is the initial temperature of the coal seam, ${ }^{\circ} \mathrm{C}$.

2.2.3. Porous Medium and Heat Transfer Fluid. The coal around the borehole chemically reacts with the outside air, and the heat released increases the temperature of the coal body around the borehole. According to the hypothesis of local heat balance, the heat transfer equation [34] for the spontaneous combustion process of coal is as follows:

$$
C_{e q} \frac{\partial T}{\partial t}+\varphi \rho_{g} C_{p g} \bar{q} \cdot \nabla T-\nabla \cdot\left(k_{e q} \nabla T\right)=-R_{c} Q_{T},
$$

where $C_{e q}$ is the heat capacity of the gas, $\mathrm{kg} \cdot \mathrm{K} ; k_{e q}$ is the thermal conductivity of the gas, $\mathrm{J} /(\mathrm{m} \cdot \mathrm{k} \cdot \mathrm{s}) ; C_{p g}$ is the heat capacity of coal, $\mathrm{J} /(\mathrm{m} \cdot \mathrm{K}) ; Q_{T}$ is the heat of oxidation, $\mathrm{kJ} / \mathrm{mol}$.

\section{Mathematical Model Construction}

3.1. General Situation of 24130 Working Face in Pingdingshan No. 10 Mine. The Pingdingshan No. 10 Coal Mine of China Pingdingshan Coal Group Co., Ltd. is an outburst coal mine. The coal seam easily undergoes spontaneous combustion. The buried depth of the No. 15 coal seam in the 24130 working face is $1200 \mathrm{~m}$. The gas drainage method mainly adopts the through-layer predraining gas technology and the gas prevention technology in the working face. The gas pressure range of the 15th and 16th coals of the No. 10 mine is $0.1-2.95 \mathrm{MPa}$, and the gas pressure range of the 17 th coal is $0.4-1.85 \mathrm{MPa}$. The amount of gas in the 15 th and 16th coals of the No. 10 mine is in the range of 2.15$20.04 \mathrm{~m}^{3} / \mathrm{t}$ and that in the 17th coal is in the range of 6.49 $12.13 \mathrm{~m}^{3} / \mathrm{t}$. The air permeability of the coal seam at the 24130 working face is $0.0019 \mathrm{MD}$, and the attenuation coefficient is $0.068 \mathrm{~d}^{-1}$. The coal seam has poor air permeability and is difficult to extract. The inclination angle of the coal seams in the mining area varies significantly. The inclination angle of the coal seams south of the Shikuang syncline is in the range of $10-20^{\circ}$, and the coal seam inclination angles from the north of the Guozhuang anticline to the Likou syncline gradually decrease from $40^{\circ}$ to $0-5^{\circ}$.
3.2. Model and Mesh. A 2D axisymmetric model is established for the spontaneous combustion of coal around a borehole induced by negative pressure drainage. The working face length (airway length) is $70 \mathrm{~m}$, the working face width (cut hole length) is $160 \mathrm{~m}$, and the depth of the borehole for gas drainage along the bedding based on an actual drilling diameter of $94 \mathrm{~mm}$, the model drilling diameter is set to $100 \mathrm{~mm}$ considering drilling disturbance. Based on the actual situation of the 24130 working face, the coal seam temperature is set to $48^{\circ} \mathrm{C}$, the sealing parameter is $20-8$ (sealing depthsealing length), and the suction pressures are 18, 23, 30, and $35 \mathrm{kPa}$. Figure 1 shows the constructed physical and geometric models. The grid is divided in a distributed manner. The maximum number of grid cells is 3.5 , the minimum number of cells is 0.045 , the maximum cell increase rate is 1.1 , and the curvature factor is 0.3 . The entire grid contains 24624 domain cells and 2546 boundary elements.

3.3. Key Parameters and Boundary Conditions. The permeability of the coal body around a drainage borehole is affected by both roadway excavation and drilling construction. The permeability and porosity of the coal body along the borehole direction decrease. The farther away from the center of the borehole, the lower the porosity and permeability. According to literature [32], the formula for the plastic zone radius is as follows:

$$
R_{L}=a_{0}\left[\frac{\left(p_{2}+c \cot \varphi\right)(1-\sin \varphi)}{p_{4}+c \cot \varphi}\right]^{(1-\sin \varphi) /(2 \sin \varphi)},
$$

where $a_{0}$ is the drilling radius, $\mathrm{mm} ; \varphi$ is the internal friction angle of the rock mass, ${ }^{\circ} ; c$ is the cohesion of the rock mass, $\mathrm{MPa}$; and $p_{4}$ is the support resistance, MPa.

Spontaneous combustion mainly occurs around the borehole; therefore, the coal around a single borehole is selected as the main calculation area. The main parameters of this model (Table 1) are from experimental results and references $[30,35]$. Based on the actual situation, the initial and boundary conditions are listed in Table 1. Figure 1 shows the model of the spontaneous combustion around the borehole induced by gas drainage. No displacement constraints were applied to the upper, left, and right sides of the model boundary. The initial conditions of the gas-air seepage pressure conditions are $P_{2}(0)=1.6 \mathrm{MPa}$ and $P_{3}(0)=0.1 \mathrm{kPa}$. The initial oxygen concentration is 0 , the initial roadway temperature is $28^{\circ} \mathrm{C}$, and the pressure of $\mathrm{AB}$ and $\mathrm{BC}$ is set to $0.1 \mathrm{kPa}$; GH, FG, and IH are $P_{2}(0)=1.6 \mathrm{MPa}$, oxygen convection $\mathrm{AB}$ and $\mathrm{BC}$. The oxygen concentration at the boundary is $9.375 \mathrm{~mol} / \mathrm{m}^{3}$; $\mathrm{CD}, \mathrm{FG}$, and $\mathrm{IH}$ have no diffusive convection; $\mathrm{AB}, \mathrm{BC}, \mathrm{GH}$, and $\mathrm{IH}$ have a thermal convection boundary; and $\mathrm{CD}$ and FG are adiabatic.

Table 1 lists the main parameters of the model. Based on a field test, the test borehole depth of the 24130 working face was set to $1200 \mathrm{~m}$; the average bulk density of the overlying rock mass was $2.7 \times 10^{4} \mathrm{~N} \cdot \mathrm{m}^{-3}$; the cohesive force was 2.1 MPa. The internal friction angle of the rock mass was $25^{\circ}$. The support resistance was $0.09 \mathrm{MPa}$. Substituting these parameters into Equation (9), we obtain $R_{L}=0.25 \mathrm{~m}$. The 


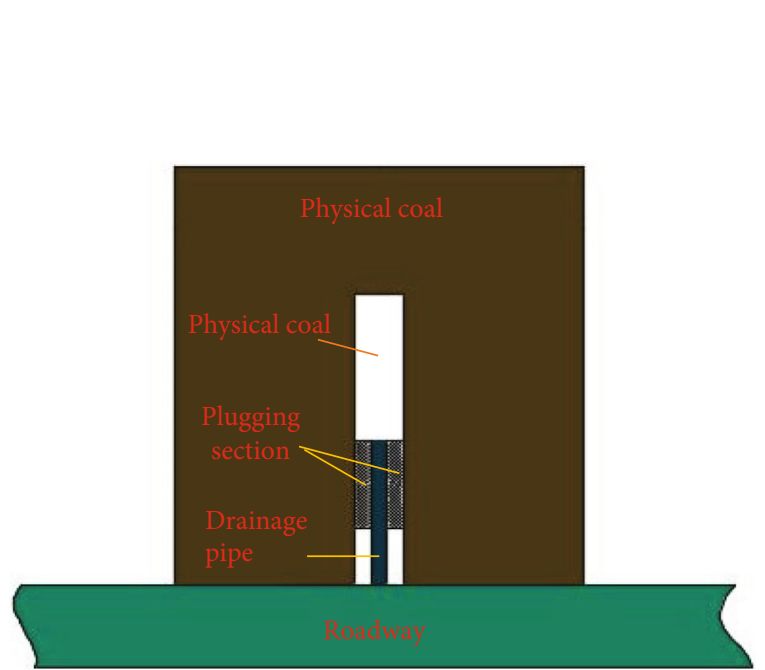

(a)

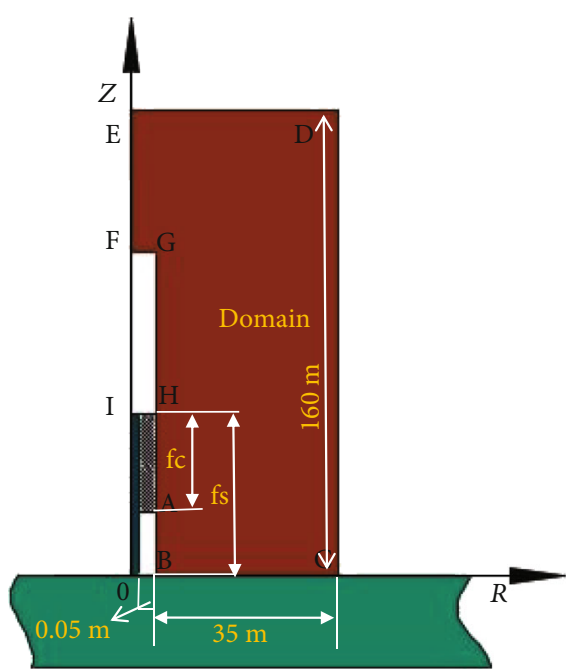

(b)

Figure 1: (a) Physical model and (b) simulation model of drainage borehole.

TABLe 1: Model parameters.

\begin{tabular}{lccr}
\hline Parameters & Magnitude and unit & Parameters & Magnitude and unit \\
\hline Coal density & $1250\left(\mathrm{~kg} / \mathrm{m}^{3}\right)$ & Initial oxygen volume fraction & $9.375\left(\mathrm{~mol} / \mathrm{m}^{3}\right)$ \\
Original coal permeability & $0.039\left(\mathrm{~m}^{2}\right)$ & Heat transfer coefficient & $180\left(\mathrm{~W} /\left(\mathrm{m}^{2} \cdot \mathrm{K}\right)\right)$ \\
Methane heat capacity & $1625(\mathrm{~J} /(\mathrm{kg} \cdot \mathrm{K}))$ & Gas viscosity & $1.84 \times 10^{-5}(\mathrm{~Pa} \cdot \mathrm{s})$ \\
Coal heat capacity & $1260(\mathrm{~J} /(\mathrm{kg} \cdot \mathrm{K}))$ & Air viscosity & $1.79 \times 10^{-5}(\mathrm{~Pa} \cdot \mathrm{s})$ \\
Molar air mass & $0.029(\mathrm{~kg} / \mathrm{mol})$ & Oxygen consumption constant & $0.036\left(\mathrm{~mol} /\left(\mathrm{m}^{3} \cdot \mathrm{h}\right)\right)$ \\
Oxygen diffusion coefficient & $1.6 \times 10^{-4}\left(\mathrm{~m}^{2} / \mathrm{s}\right)$ & Thermal conductivity of coal & $0.26(\mathrm{~J} /(\mathrm{m} \cdot \mathrm{s} \cdot \mathrm{K}))$ \\
Oxidation heat of coal & $19744.37(\mathrm{~J} / \mathrm{g})$ & & \\
\hline
\end{tabular}

empirical formula for the borehole permeability obtained by Louis [29] is expressed in Equation (10). Equation (11) expresses the coal seam permeability around the borehole at the 24130 working face of Pingdingshan No. 10 Mine:

$$
\begin{aligned}
& k=k_{0} e^{\eta(b-x)}, \\
& k=0.039 e^{1.4(0.156-x),}
\end{aligned}
$$

where $k_{0}$ is the initial coal seam permeability, $\mathrm{m}^{2} ; b=R_{L}-r_{0}$ is the width of the plastic zone, $\mathrm{m} ; \eta$ is the permeability growth coefficient of the equivalent fissure field around the borehole, taking a value of 1.4 ; and $x$ is the coal permeability at a distance from the borehole center, $\mathrm{m}$.

\section{Analysis of the Temporal and Spatial Evolution Laws of Coal Spontaneous Combustion Induced by Negative Pressure Drainage}

The wind speed of the gas leakage around the gas drainage borehole is a vector, and it is difficult to measure it during the gas drainage process. The oxygen concentration is affected by both the air leakage state and the oxygen state.
The area with a higher oxygen concentration has serious air leakage, the area with a high natural degree consumes more oxygen, and the oxygen concentration is low. The oxygen content reflects the supplying conditions of the coal body around the borehole and the heat storage conditions. The temperature of the coal body around the borehole is the most direct indicator reflecting the spontaneous combustion state around the borehole. Because the surrounding environment of the borehole is complicated, it is difficult to detect the internal temperature of the borehole [31]. Therefore, the numerical simulation method is used to study the spatial evolutions of the gas leakage streamlines, wind speed distribution, oxygen concentration, and temperature around the borehole under different suction negative pressure conditions.

4.1. Influence of Negative Pressure on the Gas Seepage Velocity around a Borehole. Figure 2 shows cloud diagrams of the gas seepage velocity around a gas drainage borehole, where the plugging depth is $20 \mathrm{~m}$, the plugging length is $8 \mathrm{~m}$, and the coal seam temperature is $48^{\circ} \mathrm{C}$. As shown, the gas around the drainage borehole mainly flows from the roadway wall and the exposed borehole into the gas drainage pipe. The gas seepage gradient around the gas drainage borehole is high, and the gas gradient area is large. The main channel for gas leakage is via the extraction borehole. In Figures 2(a)-2(d), the seepage 


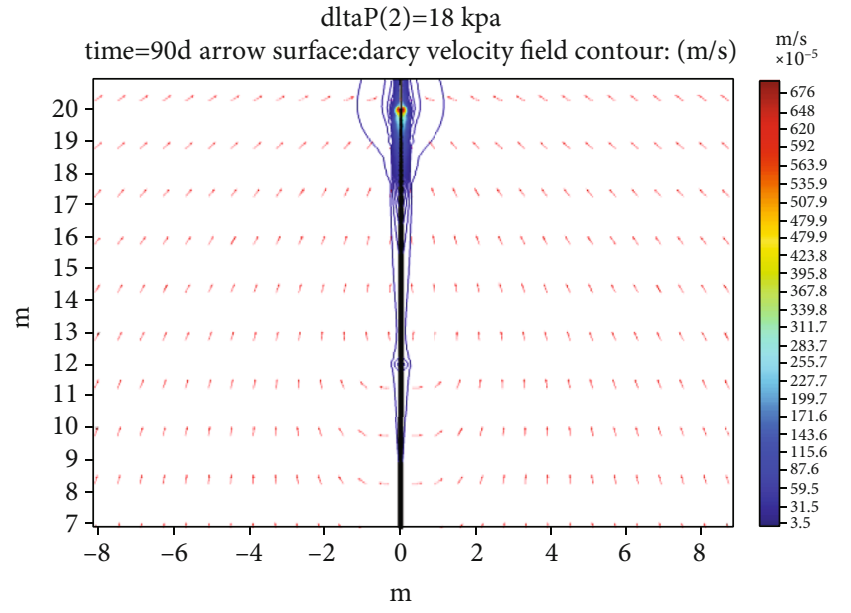

(a)

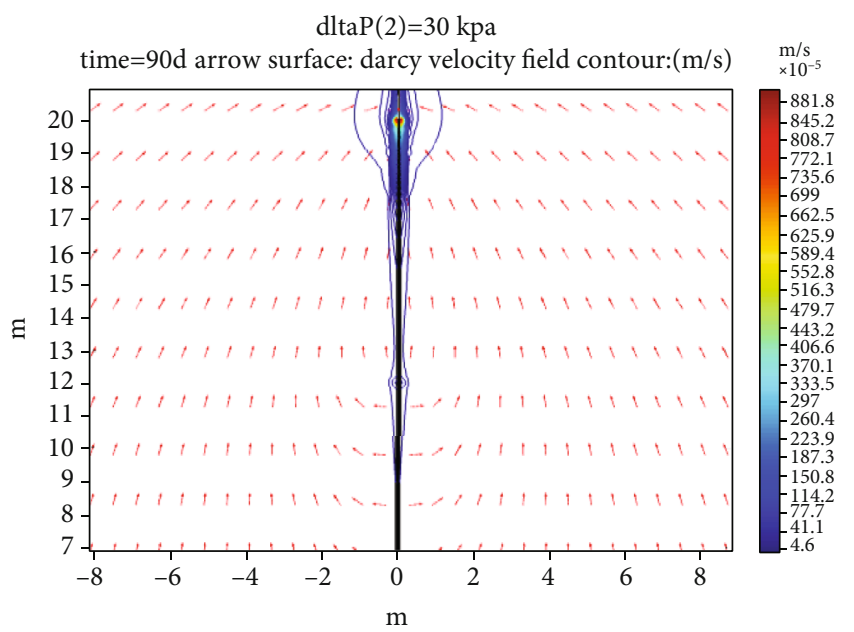

(c)

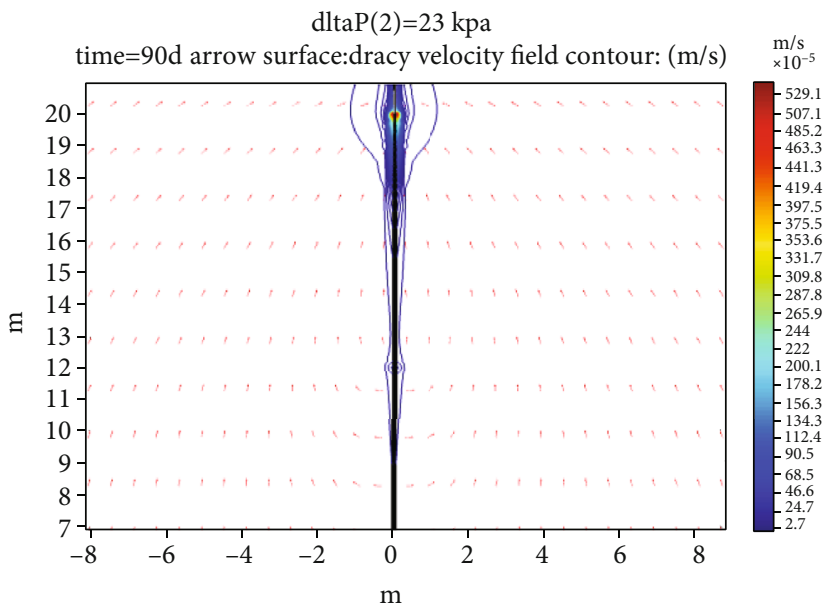

(b)

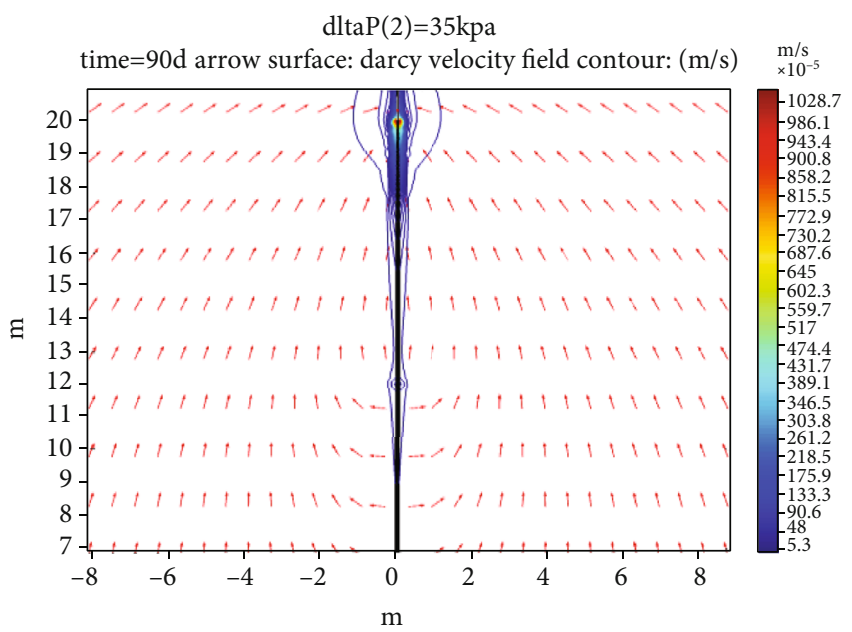

(d)

FIGURE 2: Cloud maps of the gas seepage velocity around a gas drainage borehole under suction pressures of (a) $18 \mathrm{kPa}$, (b) $23 \mathrm{kPa},(\mathrm{c}) 30 \mathrm{kPa}$, and (d) $35 \mathrm{kPa}$.

velocity on the inner side of the plugging section of the gas drainage borehole is the highest, and when the negative pressures of drainage are $18,23,30$, and $35 \mathrm{kPa}$, the maximum wind speeds at the inner end of the plugging section are $0.0053,0.0068,0.0081$, and $0.01 \mathrm{~m} / \mathrm{s}$, respectively. With the increase in the plugging depth, the maximum velocity of the gas around the plugging section decreases, showing a negative correlation. In the range of $12-17 \mathrm{~m}$ in the plugging section, the wind flow velocity remains largely unchanged. The greater the negative pressure of drainage, the greater the gas seepage velocity around the gas drainage borehole; the two are positively correlated. The function relationship between the maximum gas seepage velocity around the gas drainage borehole and the negative pressure of drainage is $y$ $=2.6 \times 10^{-4} x+5.72 \times 10^{-4}, R^{2}=0.98$, where $x$ is the suction negative pressure $(\mathrm{kPa})$, and $y$ is the gas seepage velocity $(\mathrm{m} / \mathrm{s})$. The closer to the center of the gas drainage borehole, the greater the gradient of seepage increase, and the denser the seepage distribution line in the figure, the faster the increase in the seepage velocity of the surrounding gas.
Figure 3 shows the seepage distribution law of the monitoring points around the plugging section with different plugging parameters under different suction pressure conditions. The legend "18-20-0.1" indicates that the negative pressure of drainage is $18 \mathrm{kPa}$, the sealing depth is $20 \mathrm{~m}$, and the distance from the center of the borehole is $0.1 \mathrm{~m}$. Figures 3(a) and 3(b) show the seepage velocity distributions at $R=0.1 \mathrm{~m}$ and $R=0.4 \mathrm{~m}$, respectively. As shown, when the sealing depth is $20 \mathrm{~m}$, the sealing length is $8 \mathrm{~m}$, and $R=0.1 \mathrm{~m}$, the maximum wind speed around the plugging section increases with the increase in the inspiratory pressure, and there is a positive correlation between them. In the distance range of $0-7 \mathrm{~m}$ in the plugging section, the seepage air flow velocity is low. In this area, combined with the distribution law of the oxygen volume fraction, the oxygen volume fraction is greater than $8 \%$, and when the wind velocity is low, the coal body is prone to spontaneous combustion. In the range of 7-10 $\mathrm{m}$, the airflow velocity around the plugging section has an exponential relationship with the distance of the outer port of the plugging section. Here, the airflow 


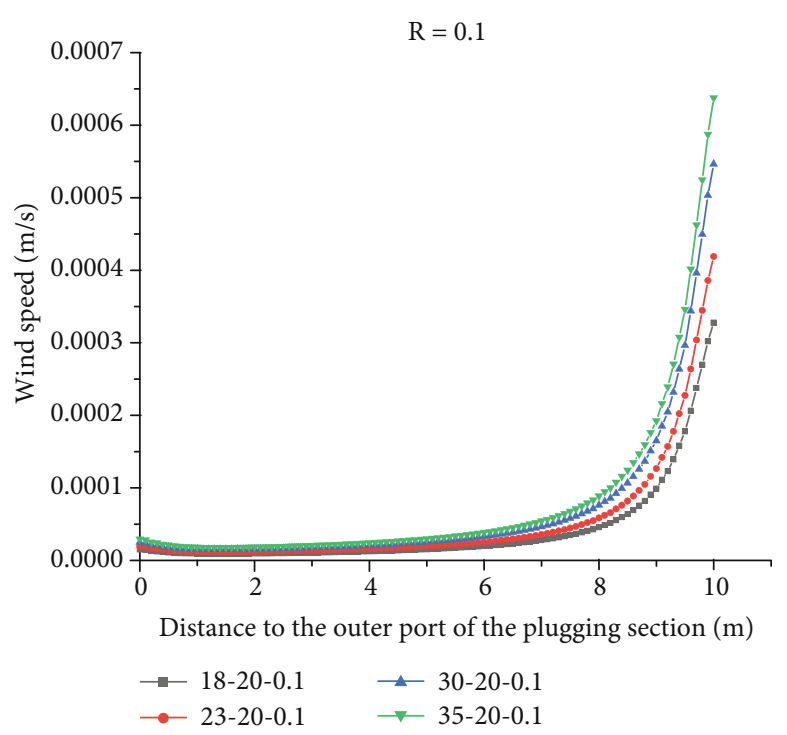

(a) $R=0.1$

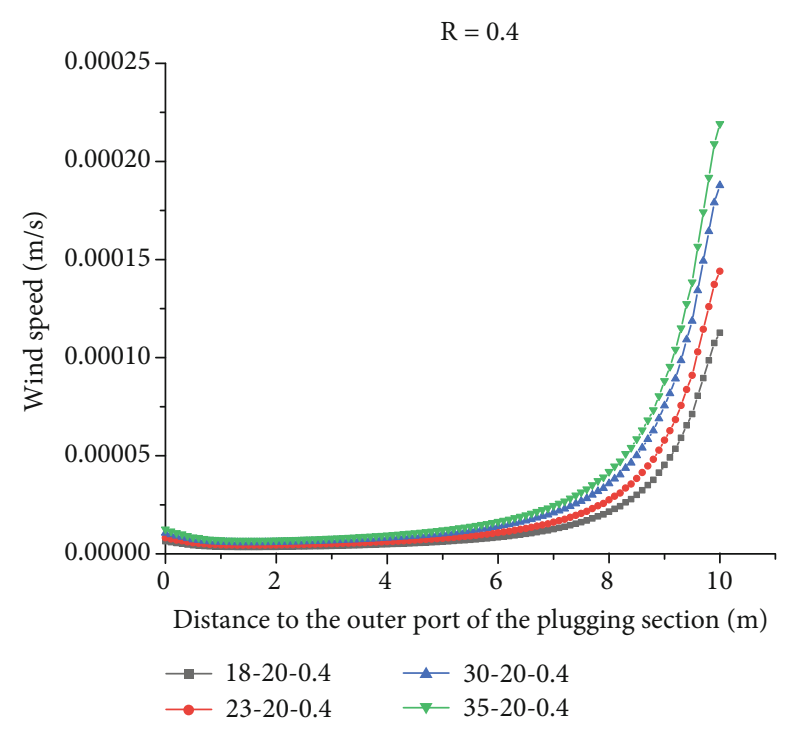

(b) $R=0.4$

FIGURE 3: Relationship between air velocity and pumping negative pressure.

velocity is high, the oxygen volume fraction is low, and the surrounding coal is not prone to spontaneous combustion. The seepage distribution law at $R=0.4 \mathrm{~m}$, shown in Figure 3(b), is lower than that shown in Figure 3(a), and the increase rate of the seepage in the range of $6-10 \mathrm{~m}$ is evidently reduced.

4.2. Influence of Negative Pressure on the Volume Fraction of Oxygen around the Borehole. The negative pressure of the drainage directly affects the pressure distribution of the fractured coal in the plugging section around the drainage borehole, which leads to the size of the gas and oxygen distribution range in the roadway. Figure 4 shows the variation in the oxygen volume fraction around the plugging section with the gas drainage time when the plugging depth is $20 \mathrm{~m}$, the plugging length is $8 \mathrm{~m}$, and the negative pressures are $18,23,30$, and $35 \mathrm{kPa}$. The legend dltaP $=18000 \mathrm{~Pa}$, $(0.5,15)$ implies that the plugging depth is $15 \mathrm{~m}$, the plugging length is $8 \mathrm{~m}$, the suction pressure is $18 \mathrm{kPa}$, and the location of the monitoring point is $0.5 \mathrm{~m}$ from the borehole radial distance and $15 \mathrm{~m}$ from the roadway wall.

Figure 4 shows the variation in the oxygen volume fraction over time at each monitoring point for different suction pressures with a sealing depth of $20 \mathrm{~m}$ and a sealing length of $8 \mathrm{~m}$. As shown, the monitoring point moves to the inner side of the plugging section, and the oxygen volume fraction decreases; the oxygen volume fraction at each monitoring point hardly changes with the progress of gas drainage. As shown in Figures 4(a) and 4(b), at suction negative pressures of 18 and $23 \mathrm{kPa}$, respectively, the oxygen volume fraction is $<8 \%$, and the sealing section lengths are 5 and $4 \mathrm{~m}$, respectively. The greater the negative pressure, the wider the range of oxygen diffusion. Within 90 days of gas drainage, the oxygen volume fraction was relatively stable, and the downward trend was relatively slow, indicating that the coal body around the borehole was in a slow oxidation stage and that there was no spontaneous combustion. As shown in Figures 4(c) and 4(d), at negative extraction pressures of 30 and $35 \mathrm{kPa}$, the oxygen volume fraction is $<8 \%$ in the distance range of $16 \sim 20 \mathrm{~m}$ from the roadway, with no conditions for a spontaneous ignition. Between $16 \mathrm{~m}$, the oxygen volume fraction is $>8 \%$, and the inflection point appears at extraction times of $60 \mathrm{~d}$ and $52 \mathrm{~d}$, that is, the point where the oxygen volume fraction begins to drop rapidly. At this time, the surrounding fractured coal enters the rapid oxidation stage. In summary, with the increase in the negative pressure of extraction, the narrower the range of the coal suffocation zone around the plugging section, the earlier the rapid decline in the oxygen concentration, and the shorter the time required by the fissured coal around the plugging section to ignite. Therefore, when the sealing depth is $20 \mathrm{~m}$ and the sealing length is $8 \mathrm{~m}$, the oxygen volume fraction is used to determine whether spontaneous combustion occurs in the coal as the standard, and the suction pressure should not be $>23 \mathrm{kPa}$.

4.3. Influence of Negative Pressure on Coal Temperature around Borehole. Figures 5(a)-5(d) show that when the plugging depth is $20 \mathrm{~m}$, the plugging length is $8 \mathrm{~m}$, and the suction pressures are $18,23,30$, and $35 \mathrm{kPa}$, respectively, the fissure coal around the plugging section is in the 90th day of gas drainage. The body temperature distribution cloud chart shows that with the increase in the suction pressure, the high-temperature areas around the gas drainage boreholes where the coal temperature is $>70^{\circ} \mathrm{C}$ expand, and the highest values of the coal body temperature reach $71.3,83.4,106$, and $128^{\circ} \mathrm{C}$. The high-temperature area is within the range of $0-$ $2 \mathrm{~m}$ from the outer end of the plugging section. The oxygen concentration in this area is high, and the seepage velocity is low, which are conducive to produce and store heat. In summary, when the plugging depth is $20 \mathrm{~m}$ and the plugging length is $8 \mathrm{~m}$, to prevent the spontaneous combustion, the 


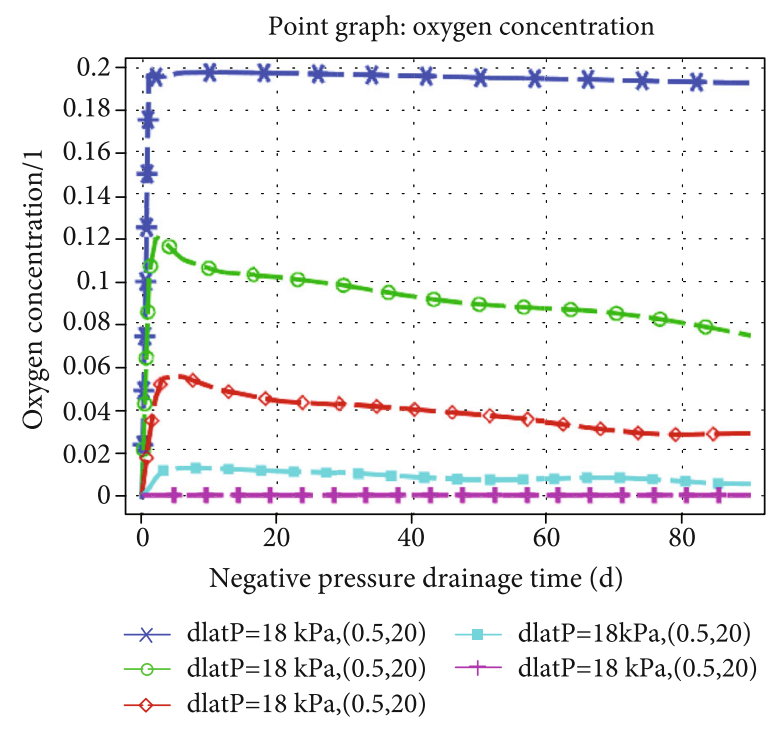

(a)

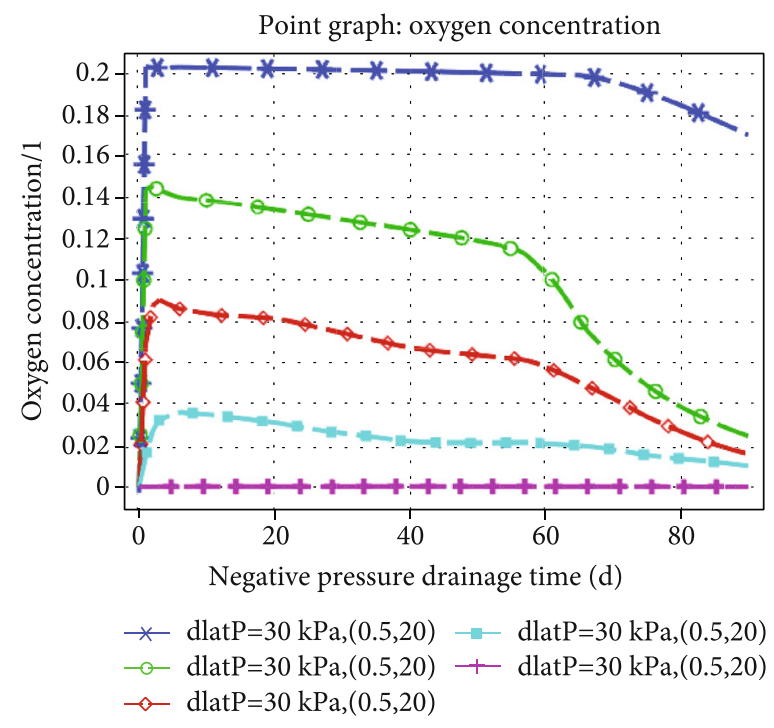

(c)

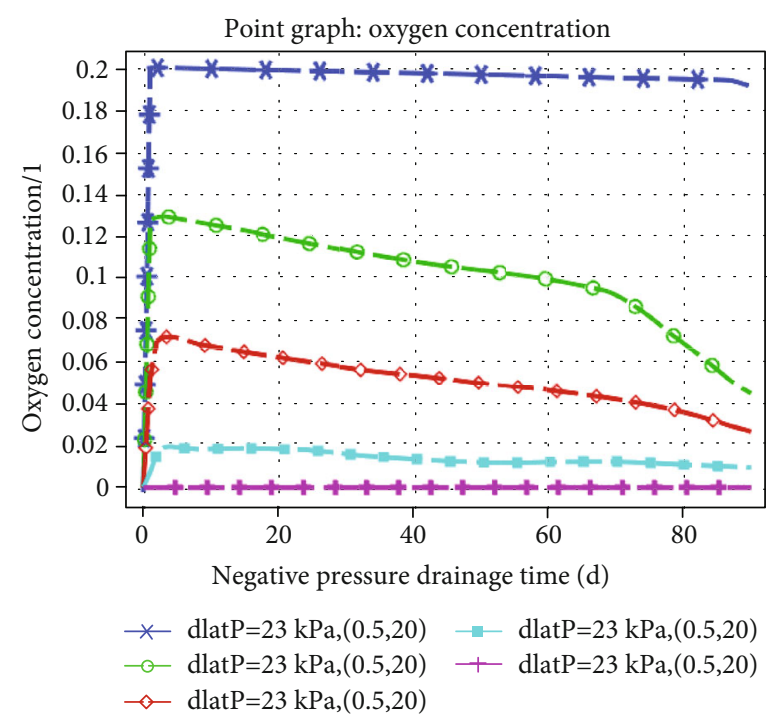

(b)

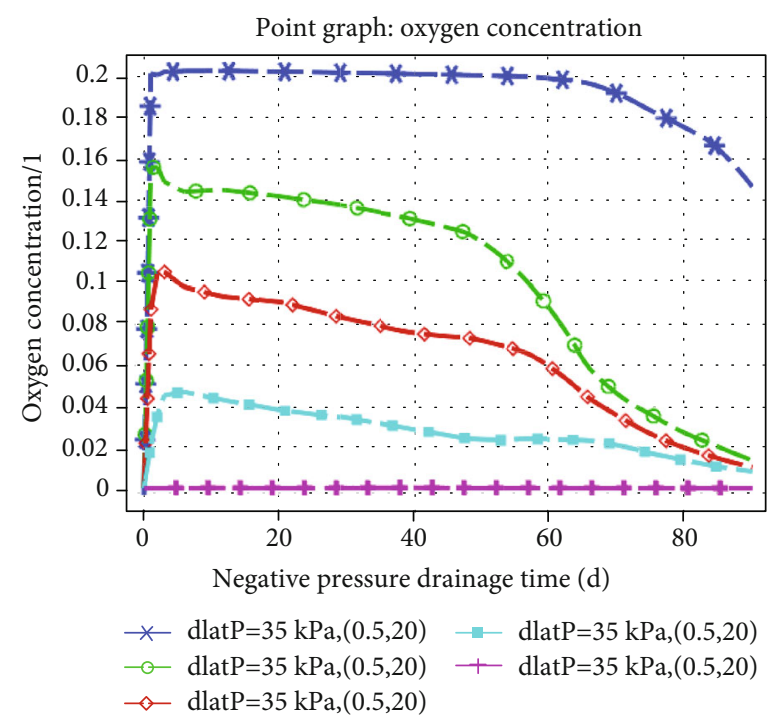

(d)

Figure 4: Change law of the oxygen concentration at different monitoring points for suction pressures of (a) $18 \mathrm{kPa}$, (b) $23 \mathrm{kPa}$, (c) $30 \mathrm{kPa}$, and (d) $35 \mathrm{kPa}$.

negative pressure of the drainage should not exceed $18 \mathrm{kPa}$ when the gas drainage time is within 90 days.

Figure 6 shows the temporal and spatial evolutions of the coal temperature around the borehole under different drainage negative pressure conditions at positions $(0.5,12),(0.5$, $15),(0.5,17.5)$, and $(0.5,20)$. Figure $6(\mathrm{a})$ shows the monitoring point $(0.5,12)$ outside the plugging section. The temperature of the coal body increases with the increase in the gas drainage time, exhibiting a linear trend, and the negative pressure of the drainage increases. The higher the temperature of the coal body around the borehole, when the suction pressure is $35 \mathrm{kPa}$, the coal temperature reaches $105^{\circ} \mathrm{C}$. Figures 6(b) and 6(c) show the evolution laws of the coal body temperature at the monitoring points $(0.5,15)$ and $(0.5,17.5)$. As shown, when the negative pressure of drainage is $>30 \mathrm{kPa}$, the gas drainage is approximately 70 days, and the temperature of the coal body begins to decrease, indicating that the heat dissipation of the coal body is greater than the heat generation. This is mainly because as the degree of coal oxidation increases, the area outside the plugging section consumes a large amount of oxygen; therefore, the closer the plugging section is to the inner side, the more the oxygen consumed and the lower the heat released, thereby decreasing the temperature of the coal body. Figure $6(\mathrm{~d})$ shows that the coal at the monitoring point $(0.5,20)$ has largely no change in its temperature. This is mainly due to the fact that it is close to the inner side of the plugging section, the gas seepage velocity is high, the oxygen concentration is low, and the heat dissipation is significantly lower than the heat production. The low temperature increase is also due to the heat conduction of the gas. In summary, along the drilling direction, on both sides of the plugging section, the 


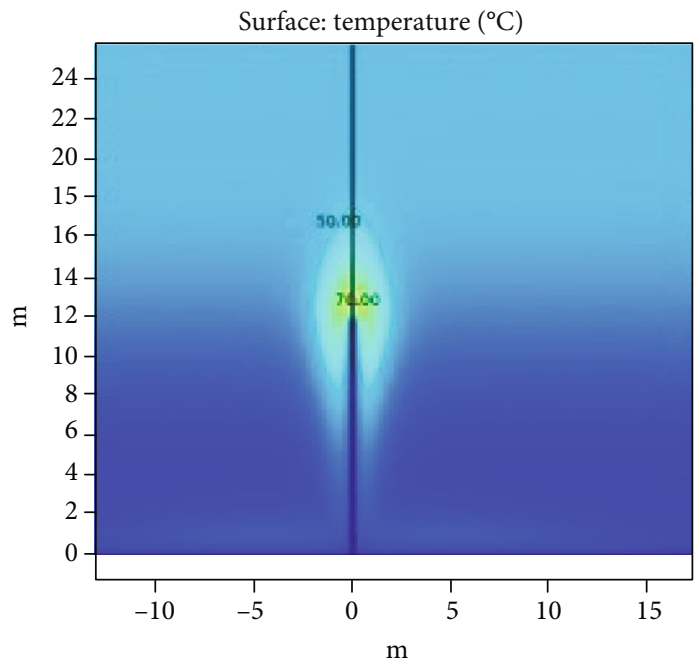

(a)

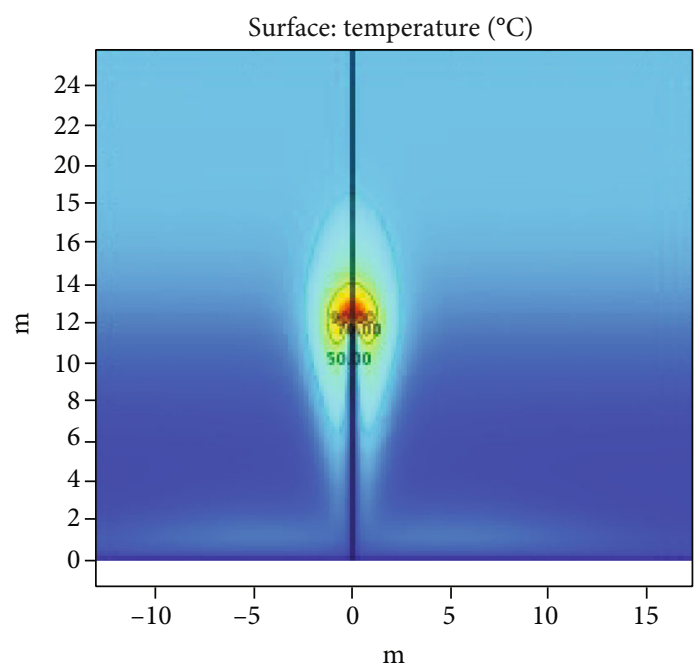

(c)

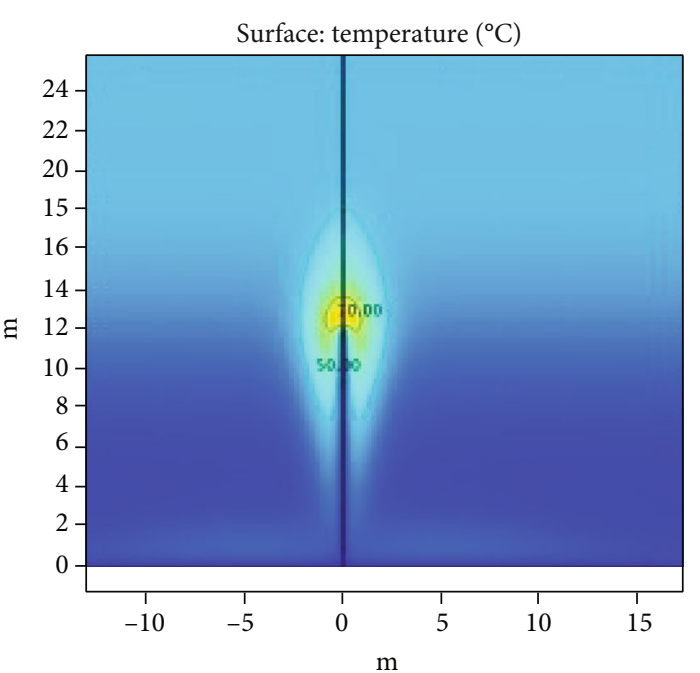

(b)

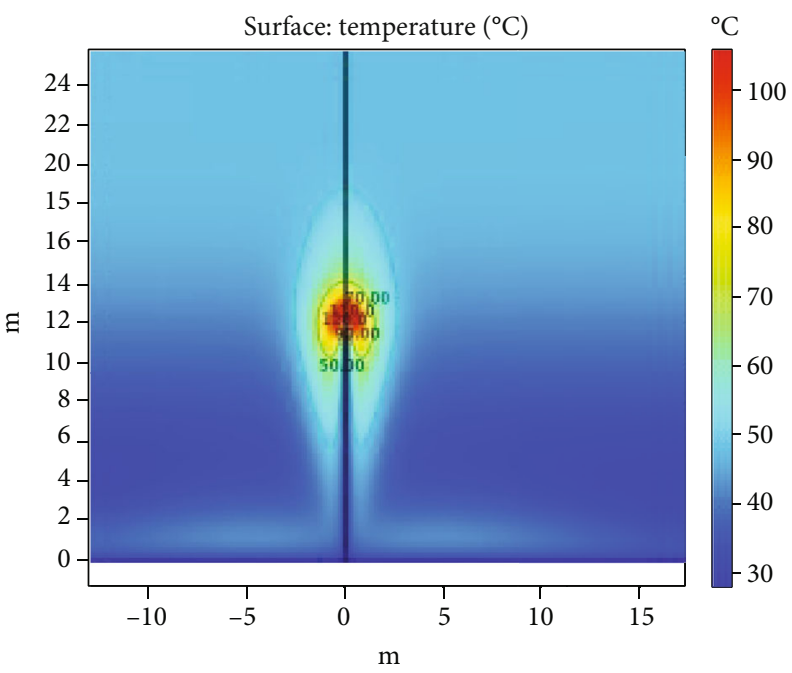

(d)

FIGURE 5: Coal temperature cloud maps around a gas borehole at suction pressures of (a) $18 \mathrm{kPa}$, (b) $23 \mathrm{kPa}$, (c) $30 \mathrm{kPa}$, and (d) $35 \mathrm{kPa}$.

maximum temperature of the coal body temperature decreases, and the area outside the plugging section has the highest heating rate. It is also most prone to fire area and is important for prevention and treatment.

4.4. Model Validation. In this study, the test boreholes in the conveyor roadway of the 24130 working face were taken as examples for a comparative verification. Each test borehole was equipped with two $\mathrm{AD} 590 \mathrm{JH}$ temperature sensors to monitor the temperature at two positions $12 \mathrm{~m}$ and $14 \mathrm{~m}$ away from the borehole orifice. Figure 7 shows the temperature at the numerical simulation point and the test monitoring point. As shown, with the increase in the gas drainage time, the surrounding coal temperature increases. The coal temperature around the borehole at the test point is lower than the simulated point at the test point, and the temperature at the test point $(0.5,12)$. The initial stage is less than $(0.5,14)$, but with the increase in the time, when the gas drainage time is $60 \mathrm{~d}$, the coal body temperature $(0.5,12)$ on the outer side is higher than $(0.5,14)$. In the early stage of gas drainage, the heat release of coal oxidation at a lower temperature is lower, and the closer to the outside, the greater the heat dissipation. With the increase in the gas drainage time, the coal near the outside $(0.5,12)$ is sufficient. The oxidation reaction is accelerated under oxygen conditions, the heat production is far greater than the heat dissipation, and the heating rate is accelerated. Comparing the temperature changes at $(0.5,12)$ between the simulated and experimental points, the simulation results are largely consistent with the changes in the field test data. The average coal temperature at the simulated point within 90 days is calculated to be $56.4^{\circ} \mathrm{C}$. The average coal temperature is $52^{\circ} \mathrm{C}$. Similarly, it can be calculated that the average coal temperature within 90 days of gas drainage at $(0.5,14)$ is $52.6^{\circ} \mathrm{C}$, and the temperature at the simulation point is $56.8^{\circ} \mathrm{C}$. The errors between the average coal temperature at $(0.5,12)$ and $(0.5,14)$ of the numerical simulation monitoring point and the average coal temperature of the test point are $7.8 \%$ and $7.4 \%$. The error is 


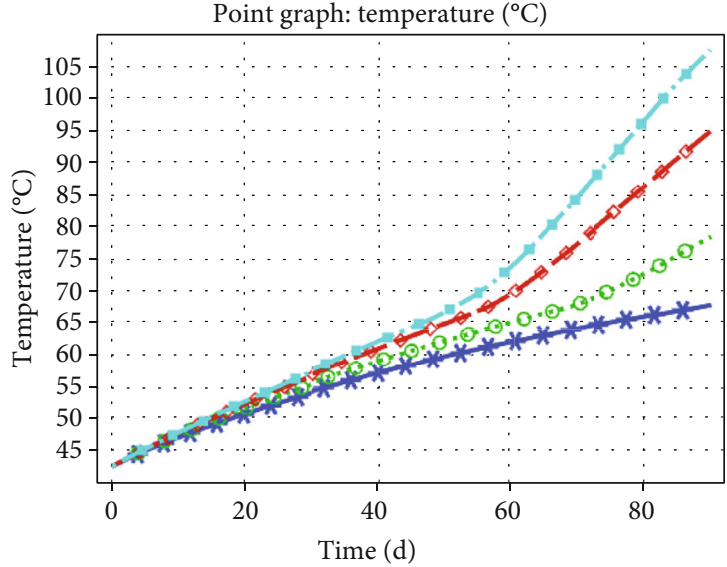

(a)

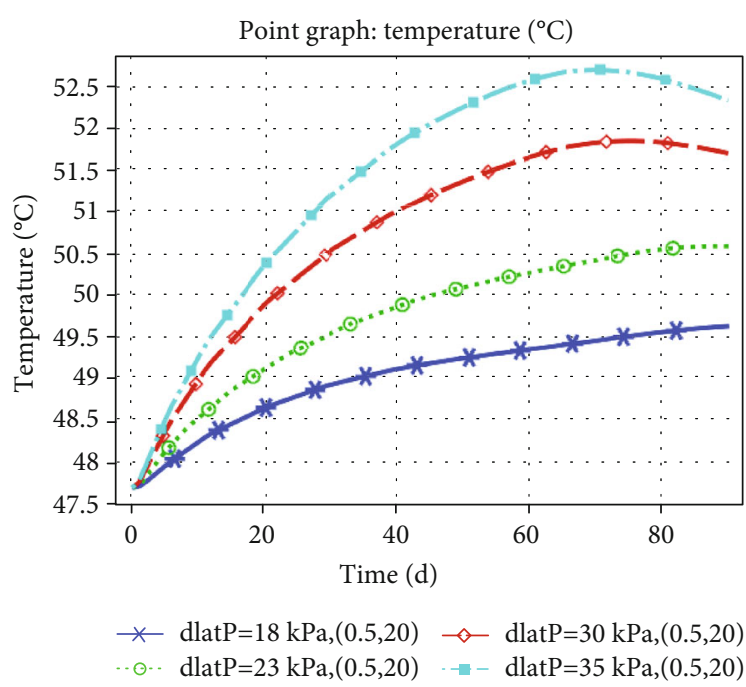

(c)

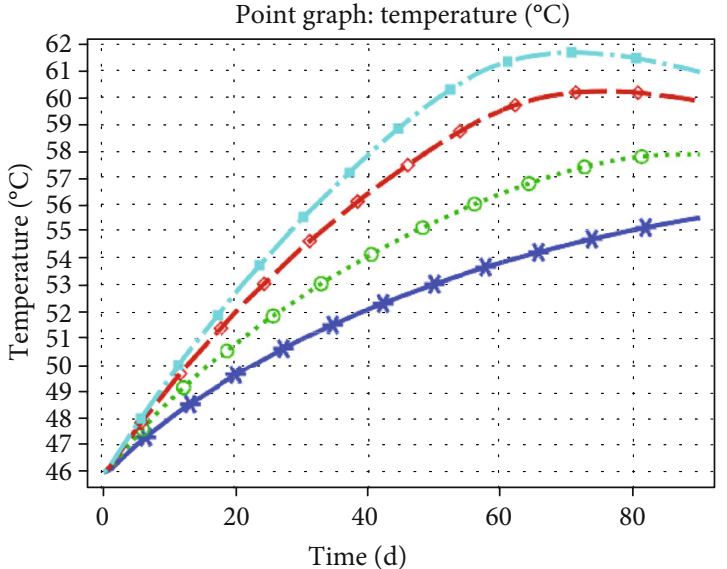

(b)

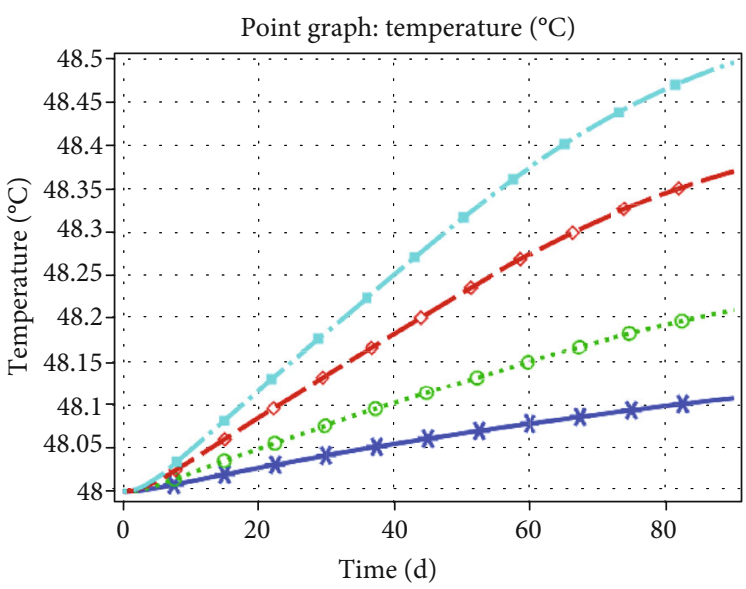

(d)

Figure 6: Temporal and spatial evolutions of the temperature in the coal body around a borehole at different monitoring points: (a) $(0.5,12)$, (b) $(0.5,15),(c)(0.5,17.5)$, and (d) $(0.5,20)$.

low, and the monitoring value is in good agreement with the numerical simulation value, indicating the reliability of the numerical simulation. Similarly, by monitoring the temperature in the borehole using the beam tube, the $\mathrm{CO}$ volume fraction in the beam tube was detected. Figure 8 shows the obtained data results. The figure shows that the $\mathrm{CO}$ volume fraction increases with the increase in the gas drainage time. The CO concentration in the borehole in the early stage of drainage is much lower than that in the later stage of gas drainage, which is largely consistent with the temperature change as the drainage progresses. From the side, the spontaneous combustion of coal around the drainage borehole is verified, which further confirms the model accuracy.

\section{Conclusion}

To effectively solve the complex problems of gas drainage efficiency and spontaneous combustion of coal around boreholes, we applied Darcy's law, porous media, mass fluid transfer, and porous media heat transfer to establish a spon- taneous combustion model for drainage boreholes. The temporal and spatial evolution laws of the borehole gas seepage velocity, concentration, and coal temperature under different negative pressures were determined. The following results were obtained:

(1) Using the theory of porous medium seepage and heat transfer, the changes in the crack coal seepage field and temperature field around a gas extraction hole were simulated, and the influence of negative pressure on the spontaneous combustion of a cracked coal body was analyzed. Based on the actual situation in the 24130 working face of the Pingdingshan No. 10 Mine, a theoretical analysis method was used to obtain a function formula for the permeability around the borehole under gas drainage in the working face: $k=$ $0.039 e^{1.4(0.156-x)}$. From the formula, we find that the permeability and porosity of the coal body decrease exponentially; the farther the distance from the borehole center, the lower the porosity and permeability 


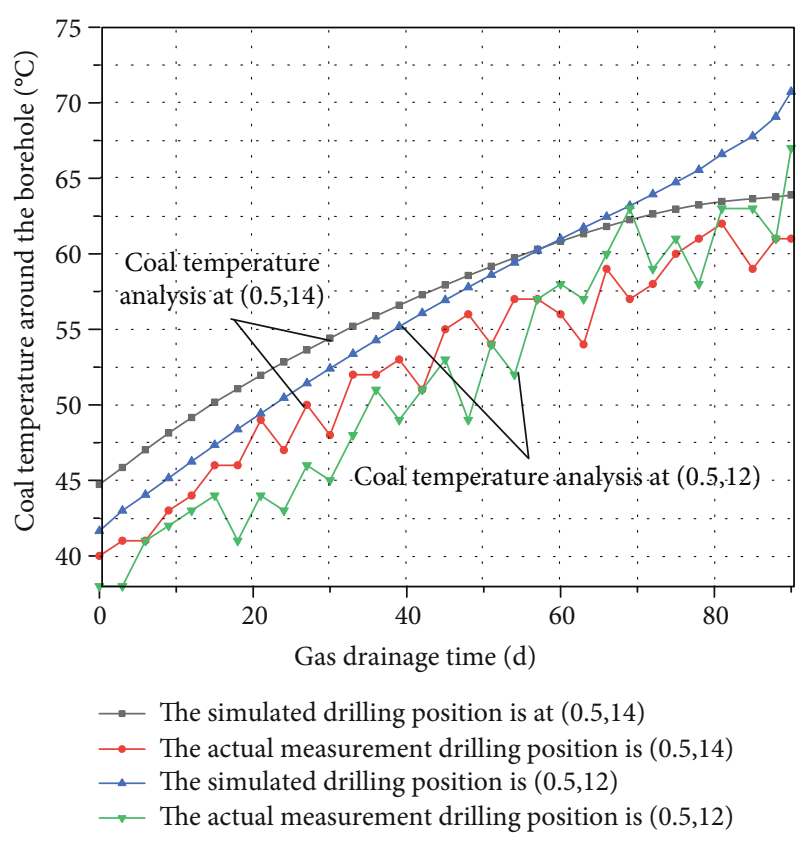

FIGURE 7: Comparative analysis of simulation and experiment.

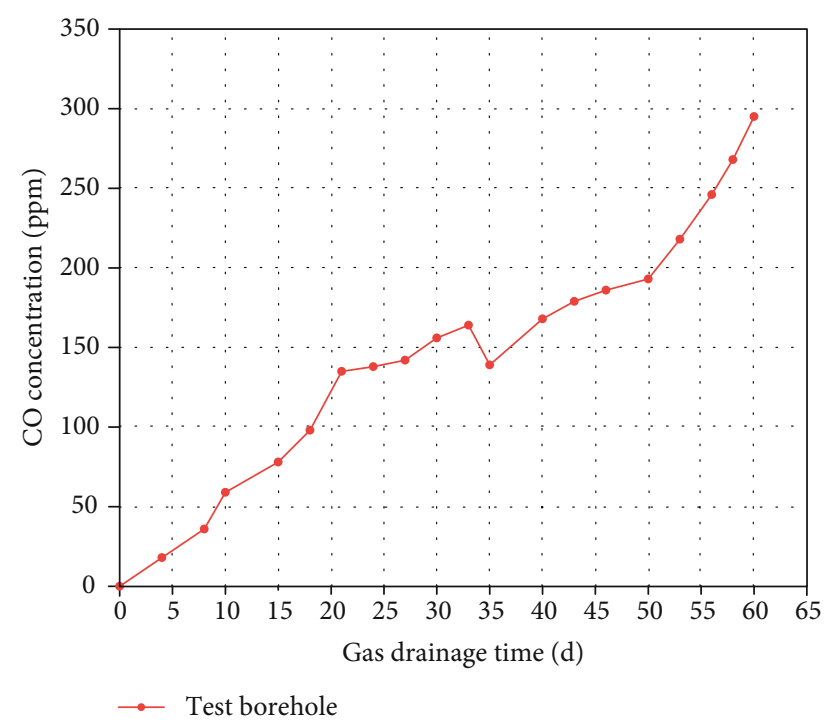

FIGURE 8: CO concentration changes in experimental boreholes.

(2) A mathematical model of the negative pressure drainage inducing coal spontaneous combustion around the borehole was established. The gas flow velocity increased with the increase in the negative pressure of the drainage, exhibiting a linear growth trend, and the negative pressure of the drainage increased. The narrower the range of the coal suffocation zone around the plugging section, the earlier the rapid decline in the oxygen concentration, the higher the temperature of the coal around the borehole, and the wider the high-temperature area. The hightemperature area around the borehole is at a distance from the outside of the sealing within 1-2 $\mathrm{m}$. At the outer end of the borehole plugging section to the inner 1-2 m location, the occurrence of heat storage and spontaneous combustion is first observed; it then spread to both ends of the borehole

(3) The oxygen concentration in the fissures around the borehole, gas seepage velocity, and coal temperature were used to determine the spontaneous combustion of the coal in the 24130 working face. When the sealing depth and sealing length are $20 \mathrm{~m}$ and $8 \mathrm{~m}$, respectively, the suction pressure should not exceed $18 \mathrm{kPa}$

\section{Data Availability}

The data used to support the findings of this study are included with the article.

\section{Conflicts of Interest}

There are no conflicts of interest regarding the publication of this paper.

\section{Acknowledgments}

The authors would like to thank Rodrigo Cabanero for the linguistic assistance during the preparation of this manuscript. This work was supported by the National Key R\&D Plan Key Special Funding Project (grant number 2018YFC0807900), China Coal Technology \& Engineering Group Co., Ltd. (2019-2-ZD003), National Natural Science Foundation Youth Project of China (grant numbers 51804161 and 51804355), National Natural Science Foundation of China (grant number 52074156), and China Postdoctoral Science Foundation (2020M680490).

\section{References}

[1] C. Wang, "Numerical simulation study on reasonable gas extraction negative pressure in the high-level entry," Industrial Safety and Environmental Protection, vol. 37, no. 1, pp. 59-61, 2011.

[2] K. Wang, X. S. Zhao, and S. G. Li, "Study on the distribution law and application of negative extraction pressure in bedding borehole," Mining Safety and Environmental Protection, vol. 48, no. 2, pp. 81-86, 2021.

[3] J. K. Ma, "Determining reasonable negative pressure of coal seam gas drainage based on statistical analysis of big data," China Energy and Environmental Protection, vol. 41, no. 5, pp. 24-27, 2019.

[4] Y. P. Cheng, J. Dong, W. Li, M. Y. Chen, and K. Liu, "Effect of negative pressure on coal bed methane extraction and application in the utilization of methane resource," Journal of China Coal Society, vol. 42, no. 6, pp. 1466-1774, 2017.

[5] K. J. Zhou, "Study on numerical simulation of negative pressure for rational extraction of coal and gas outburst seam," Coal, vol. 23, no. 2, pp. 31-33, 2014.

[6] H. Y. Wang, S. Guo, Y. Y. Xie, H. Zhao, H. Wang, and W. Wang, "Study on competitive adsorption characteristics of $\mathrm{CO} / \mathrm{CO} 2 / \mathrm{CH} 4$ multi-component low concentration gases in coal," Energy Sources, Part A: Recovery, Utilization, and Environmental Effects, vol. 42, pp. 1-15, 2020. 
[7] P. Liu, J. Z. Fan, D. Jiang, and J. Li, "Evaluation of underground coal gas drainage performance: mine site measurements and parametric sensitivity analysis," Process Safety and Environmental Protection, vol. 148, pp. 711-723, 2021.

[8] T. D. Zhang, M. K. Pang, X. K. Jiang, W. Q. Peng, and X. Ji, "Influence of negative pressure on gas percolation characteristics of coal body in perforated drilling hole," Rock and Soil Mechanics, vol. 40, no. 7, pp. 2517-2525, 2019.

[9] Y. H. Wang, Y. Wu, and J. L. Zhang, "Research on determining optimal gas drainage negative pressure based on goaf prevention and control," China Coal, vol. 44, no. 10, pp. 143-148, 2018.

[10] Q. J. Qi, Y. X. Zhao, and X. L. Jia, "Cause analysis and prevention of spontaneous combustion in deep coal seam drilling," China Safety Science Journal, vol. 29, no. 1, pp. 37-42, 2019.

[11] Q. J. Qi, H. Wang, Z. W. Dong, Y. C. Li, and X. H. Li, “Determination on initial coal spontaneous combustion area of coal pile based on COMSOL software," Coal Science and Technology, vol. 44, no. 10, pp. 18-23, 2016.

[12] H. Wang, B. Z. Dlugogorski, and E. M. Kennedy, "Analysis of the mechanism of the low-temperature oxidation of coal," Combustion and Flame, vol. 134, pp. 107-117, 2003.

[13] H. Wang, X. Fang, F. Du et al., "Three-dimensional distribution and oxidation degree analysis of coal gangue dump fire area: a case study," Science of The Total Environment, vol. 772, p. 145606, 2021.

[14] D. Zhang, X. X. Cen, W. F. Wang et al., "The graded warning method of coal spontaneous combustion in Tangjiahui Mine," Fuel, vol. 288, p. 119635, 2021.

[15] H. Wang, B. Tan, Z. Shao, Y. Guo, Z. Zhang, and C. Xu, "Influence of different content of $\mathrm{FeS}_{2}$ on spontaneous combustion characteristics of coal," Fuel, vol. 288, p. 119582, 2021.

[16] F. Du, K. Wang, X. Zhang, C. Xin, L. Shu, and G. Wang, "Experimental study of coal-gas outburst: insights from coalrock structure, gas pressure and adsorptivity," Natural Resources Research, vol. 29, no. 4, pp. 2481-2493, 2020.

[17] F. Du and K. Wang, "Unstable failure of gas-bearing coal-rock combination bodies: insights from physical experiments and numerical simulations," Process Safety and Environmental Protection, vol. 129, pp. 264-279, 2019.

[18] W. J. Yao, J. Y. Pang, Q. Y. Ma, and H. Lyimo, "Influence and sensitivity analysis of thermal parameters on temperature field distribution of active thermal insulated roadway in high temperature mine," International Journal of Coal Science Technology, vol. 8, no. 1, pp. 47-63, 2021.

[19] M. Onifade and B. Genc, "Spontaneous combustion liability of coal and coal-shale: a review of prediction methods," International Journal of Coal Science Technology, vol. 6, no. 2, pp. 151168, 2019.

[20] Q. J. Qi, X. L. Jia, X. H. Zhou, and Y. Zhao, "Instability-negative pressure loss model of gas drainage borehole and prevention technique: a case study," PLoS One, vol. 15, no. 11, p. e0242719, 2020.

[21] Z. M. Wang, S. H. Han, Z. J. You, V. Honari, Y. Sun, and S. Zhang, "Influences of negative pressure on air-leakage of coalseam gas extraction: laboratory and CFD-DEM simulations," Journal of Petroleum Science and Engineering, vol. 196, p. 107731, 2021.

[22] T. Liu, "Modeling air leakage around gas extraction boreholes in mining-disturbed coal seams," Process Safety and Environmental Protection, vol. 141, pp. 202-214, 2020.
[23] Z. X. Li, "CFD simulation of spontaneous coal combustion in irregular patterns of goaf with multiple points of leaking air," Journal of China University of Mining and Technology, vol. 18, no. 4, pp. 504-515, 2008.

[24] H. Y. Wang, X. Y. Fang, Y. C. Li, and Z. Y. Zheng, "Research and application of the underground fire detection technology based on multi-dimensional data fusion," Tunnelling and Underground Space Technology, vol. 109, 2021.

[25] J. J. Liu, D. Wang, and J. L. Gao, "Numerical simulation of drainage negative of high alley pumping effect on the goaf air leakage and spontaneous combustion zone," Journal of Heilongjiang University of Science and echnology, vol. 26, no. 4, pp. 362-367, 2016.

[26] W. R. Zhang, S. Q. Yang, and J. W. Cheng, "Spontaneous heating and gas drainage on a coal face with 'fourgateroad' and overlying drainage tunnel," Journal of China University of Mining and Technology, vol. 42, no. 4, pp. 513-518, 2013.

[27] W. Wang, B. S. Jia, and Y. Qi, "Improved CRITIC modified G2-TOPSIS borehole spontaneous combustion prediction model and application," Chinese Safety Science Journal, vol. 29, no. 11, pp. 26-31, 2019.

[28] S. M. Li, "Study on the influence of negative pressure of gas drainage effect of coal seam," Energy Technology and Management, vol. 42, no. 3, pp. 31-36, 2017.

[29] Q. Y. Chen, Study on Law of "Three Zones" Distribution in Goaf Based on the Buried Pipe Drainage, North China University of Science and Technology, 2015.

[30] F. B. Zhou, X. Wang, and T. Q. Xia, "A model of safe drainage of coal seam gas,” Journal of China Coal Society, vol. 39, pp. 1659-1666, 2014.

[31] G. Liu and H. W. Song, "Study on the law of loose surrounding rock in coal roadway," Journal of China Coal Society, vol. 39, pp. 31-35, 2002.

[32] Y. Lu, X. Z. Zou, D. P. Cui, and X. F. Yu, "Theoretical analysis and practice of fragmentation circle in surrounding rock," Journal of Liaoning University Technology, vol. 2, pp. 219221, 2007.

[33] Z. X. Li, Q. Wu, and Z. Q. Wang, "Distribution characteristic of remaining coal oxygen consumption and spontaneous combustion heating-up in gob," Journal of China Coal Society, vol. 34, pp. 667-672, 2009.

[34] F. Tong, L. Jing, and R. W. Zimmerman, "A fully coupled thermo-hydro-mechanical model for simulating multiphase flow, deformation and heat transfer in buffer material and rock masses," International Journal of Rock Mechanics and Mining Sciences, vol. 47, no. 2, pp. 205-217, 2010.

[35] X. Jia, Q. Qi, and Y. Zhao, "Determination of the spontaneous combustion hazardous zone and analysis of influencing factors in bedding boreholes of a deep coal seam," ACS Omega, vol. 6, no. 12, pp. 8418-8429, 2021. 